\title{
Análise técnica dos novos padrões brasileiros para amônia em efluentes e corpos d'água
}

\author{
Technical analysis of the new brazilian concentration limits for \\ ammonia in effluents and bodies of water
}

\author{
José Antonio Tosta dos Reis \\ Doutor em Hidráulica e Saneamento pela Escola de Engenharia de São Carlos da Universidade de São Paulo (EESC/USP). \\ Professor da Coordenadoria de Saneamento Ambiental do Instituto Federal do Espírito Santo (Ifes)
}

Antônio Sérgio Ferreira Mendonça

Doutor em Engenharia de Recursos Hídricos pela Colorado State University. Professor do Departamento de Engenharia Ambiental da Universidade Federal do Espírito Santo (Ufes)

\section{Resumo}

Este trabalho discute os padrões estabelecidos pelas resoluções Conama 357/2005 e 397/2008 para os compostos de amônia em efluentes e corpos d'água. Os padrões estabelecidos pelas referidas resoluções são confrontados com os estabelecidos pela revogada Resolução Conama 20/1986 e com os padrões norte-americanos. As discussões permitem concluir que a Resolução Conama 357/2005 apresenta avanços em relação aos padrões anteriormente estabelecidos, incorporando a influência do pH sobre distribuição e toxicidade dos compostos amoniacais e alterando a concentração máxima aceitável para a amônia total nos efluentes. A Resolução Conama 397/2008 permite a eliminação do limite para efluentes sanitários. No entanto, as referidas resoluções não consideram a influência da temperatura sobre o comportamento dos compostos de amônia.

Palavras-chave: amônia; Resolução Conama 357/2005; Resolução Conama 397/2008.

\begin{abstract}
This paper discusses the Brazilian National Council legislation (Resolutions 357/2005 and 397/2008) standards for ammonia composts in water and effluents. Standards indicated by resolutions are compared to those from previous Conama Resolution 20/1986 and with North American standards. It is concluded that the new ammonia limit concentrations, from Resolution 357/2005 for water bodies and industrial effluents and the elimination of effluent concentration limits for sanitary effluents, by Resolution 397/2008, represent an advance over previous Brazilian standards by considering the pH influence on the distribution and toxicity of ammonia composts, increasing the maximum total ammonia concentration for industrial effluents and eliminating maximum total concentration limits for sanitary effluents. However, the Resolution 357/2005 does not take into account temperature influence on these distribution and toxicity.
\end{abstract}

Keywords: ammonia; Conama Resolution 357/2005; Conama Resolution 397/2008.

\section{Introdução}

A amônia está presente naturalmente nos corpos d'água como produto da degradação de compostos orgânicos e inorgânicos do solo e da água, resultado da excreção da biota, redução do nitrogênio gasoso da água por micro-organismos ou por trocas gasosas com a atmosfera. A amônia é, também, constituinte comum no esgoto sanitário, resultado direto de descargas de efluentes domésticos e industriais, da hidrólise da ureia e da degradação biológica de aminoácidos e outros compostos orgânicos nitrogenados. 
ou da temperatura deslocam o equilíbrio químico no sentido da amônia não-ionizada. Adicionalmente, as forças iônicas são importantes para a definição do equilíbrio entre as espécies de amônia em águas com salinidades elevadas.

O comportamento tóxico das diferentes parcelas de amônia, particularmente da forma não-ionizada, também depende das condições do meio aquático. Embora as concentrações da espécie $\mathrm{NH}_{3}$ cresçam com aumentos de $\mathrm{pH}$ e temperatura, sua toxicidade diminui (ROBINSON-WILSON; SEIM, 1975; RUBIN; ELMARAGHY, 1977; THURSTON; RUSSO; VINOGRADOV, 1981; ERICKSON, 1985).

Entre 1986 e 2005, os padrões brasileiros de qualidade para os corpos d'água e efluentes eram fixados pela Resolução 20, do Conselho Nacional do Meio Ambiente (Conama). Nessa Resolução, os padrões para os compostos de amônia eram função exclusiva da classe do corpo d'água. Com a edição da Resolução Conama 357, em 17 de março de 2005, os padrões para os compostos de amônia em água doce, além de continuarem sendo função da classe do corpo d'água, passaram a depender também do valor do $\mathrm{pH}$ da massa d'água. Nos corpos d'água salinos, no entanto, a nova Resolução apenas dilatou a concentração limite para uma das classes de corpos d'água, não estabelecendo qualquer relação entre padrão de qualidade e características físicas e químicas da água. Adicionalmente, o novo padrão de qualidade para os efluentes tornou-se menos restritivo.

A avaliação dos novos padrões estabelecidos pela Resolução 357/2005 para os compostos de amônia em corpos de água e efluentes, sinalizando avanços em relação aos antigos padrões e às suas eventuais limitações, constitui o objetivo central deste trabalho.

\section{0 equilíbrio químico dos compostos de amônia}

A dissociação da amônia ionizada em soluções aquosas pode ser representada pela Equação 1:

$\mathrm{NH}_{4}^{+}+\mathrm{H}_{2} \mathrm{O} \rightleftarrows \mathrm{NH}_{3}+\mathrm{H}_{3} \mathrm{O}^{+}$

Equação 1

Em qualquer dissociação, os íons liberados em solução são hidratados, rodeados por um conglomerado de dipólos de água. Os íons de hidrogênio liberados em solução são fortemente hidratados, formando ligações de hidrogênio com moléculas de água. Isso é muitas vezes realçado escrevendo-se o íon de hidrogênio hidratado como $\mathrm{H}_{3} \mathrm{O}^{+}$, conhecido como íon hidrônio ou oxônio.

O percentual da parcela não-ionizada na massa de amônia total pode ser determinado a partir da Equação 2:

$$
\frac{\mathrm{NH}_{3}}{100}=\frac{\left[\mathrm{NH}_{3}\right]}{\left[\mathrm{NH}_{3}\right]+\left[\mathrm{NH}_{4}^{+}\right]}
$$

Considerando-se a constante de dissociação $\mathrm{k}_{\mathrm{a}}$ da amônia ionizada, o valor de $\left[\mathrm{NH}_{4}^{+}\right]$pode ser explicitado função de $\mathrm{k}_{\mathrm{a}}$, $\left[\mathrm{NH}_{3}\right]$ e $\left[\mathrm{H}^{+}\right]$, conforme indicado pela Equação 3:

$\left[\mathrm{NH}_{4}\right]=\frac{\left[\mathrm{NH}_{3}\right] \cdot\left[\mathrm{H}^{+}\right]}{\mathrm{k}_{\mathrm{a}}}$

Equação 3

Combinando-se as duas últimas expressões e rememorando que o símbolo $\left[\mathrm{H}_{3} \mathrm{O}^{+}\right]$foi utilizado para destacar o forte processo de hidratação sofrido pelos íons de hidrogênio, obtém-se:

$\% \mathrm{NH}_{3}=\frac{\left[\mathrm{NH}_{3}\right]}{\left[\mathrm{NH}_{3}\right]+\frac{\left[\mathrm{NH}_{3}\right] \cdot\left[\mathrm{H}^{+}\right]}{\mathrm{k}_{\mathrm{a}}}}$

Equação 4

A partir das definições de $\mathrm{pH}\left(\mathrm{pH}=-\log \left[\mathrm{H}^{+}\right]\right)$e de $\mathrm{pk}_{\mathrm{a}}\left(\mathrm{pk}_{\mathrm{a}}=-\log \right.$ $\mathrm{k}_{\mathrm{a}}$ ) a Equação 4 pode ser reescrita da seguinte forma:

$\% \mathrm{NH}_{3}=\frac{1}{1+10^{\left(\mathrm{pk}_{\mathrm{a}}-\mathrm{pH}\right)}}$

Equação 5

Emerson et al. (1975) correlacionaram empiricamente a constante de dissociação da amônia ionizada em águas doces com a temperatura. Para a apropriação da constante $\mathrm{k}_{\mathrm{a}}$ Emerson et al. (1975) propuseram a adoção da Equação 6:

$\mathrm{pk}_{\mathrm{a}}=0,09018+2729,92 / \mathrm{T}$.

Equação 6

Sendo $\mathrm{T}$ a temperatura medida em $\mathrm{K}$. Combinando-se as duas últimas expressões, o percentual da fração não-ionizada de amônia em águas doces pode ser avaliado a partir da Equação 7:

$\% \mathrm{NH}_{3}=\frac{1}{1+10^{[0,09018+(2729,92 / \mathrm{T})]-\mathrm{pH}}}$

Equação 7

Clegg e Whitfield (1995), por sua vez, propuseram um modelo aplicável à avaliação da constante de dissociação da amônia ionizada em águas salinas, válido para temperaturas compreendidas no intervalo de $271 \mathrm{~K}$ a $313 \mathrm{~K}\left(-2\right.$ a $\left.40^{\circ} \mathrm{C}\right)$ e salinidades variando entre 0 e $40 \mathrm{~g} / \mathrm{kg}$. Considerando o modelo estabelecido por Clegg e Whitfield (1995), a constante de dissociação da amônia ionizada para águas salinas pode ser avaliada a partir da Equação 8:

$p k_{a}=p_{a}(T)+f_{1}(T) \cdot S^{1 / 2}+f_{2}(T) \cdot S+f_{3}(T) \cdot S^{2}+f_{4}(T) \cdot S^{3} \cdot$ Equação 8

Na Equação 8, a temperatura é medida em Ke a salinidade (S) em $\mathrm{g} / \mathrm{kg}$. As funções indicadas na Equação 8 são empíricas e assumem as formas indicadas pelas Equações de 9 a 13: 
$\mathrm{pk}_{\mathrm{a}}(\mathrm{T})=0,09087+(2729,33 / \mathrm{T})$

Equação 9

$f_{1}(T)=0,0500616-(9,412969 / T)-\left(2,029559 \cdot 10^{-7} \cdot T^{2}\right)$, Equação 10

$f_{2}(T)=-0,0142372+\left(1,46041 \cdot 10^{-5} \cdot T\right)+(3,730005 / T)$, Equação 11

$\mathrm{f}_{3}(\mathrm{~T})=7,10470 \cdot 10^{-5}-(0,00229021 / \mathrm{T})$,

Equação 12

$f_{4}(T)=-5,521278 \cdot 10^{-7}+\left(1,95413 \cdot 10^{-4} / T\right)$

Equação 13

Assim, a partir da combinação das Equações 5 a 8, considerandose as funções estabelecidas pelas Equações 9 a 13, pode-se avaliar o percentual da espécie não-ionizada de amônia em águas salinas através da Equação 14:

$$
\% \mathrm{NH}_{3}=\frac{1}{1+10^{\left(\mathrm{pk}_{\mathrm{a}}+\mathrm{f}_{1}(\mathrm{~T}) \cdot \mathrm{S}^{1 / 2}+\mathrm{f}_{2}(\mathrm{~T}) \cdot \mathrm{S}+\mathrm{f}_{3}(\mathrm{~T}) \mathrm{S}^{2}+\mathrm{f}_{4}(\mathrm{~T}) \cdot S^{3}-\mathrm{pH}\right)}}
$$

Equação 14

Com auxílio da Equação 7 foram calculados, para águas doces (salinidade igual a zero), os percentuais de $\mathrm{NH}_{3}$ nas concentrações de amônia total. Esses resultados estão reunidos na Tabela 1 .

A partir da aplicação da Equação 14, foram avaliados, para águas salinas, os percentuais de amônia não-ionizada nas concentrações de nitrogênio amoniacal total. As Tabelas 2, 3 e 4 apresentam os resultados obtidos para as águas com salinidade variando entre 10 e $30 \mathrm{~g} / \mathrm{kg}$. É importante observar que a expressão proposta por Clegg e Whitfield (1995) conduz a resultados muito próximos daqueles produzidos a partir da expressão estabelecida

por Emerson et al. (1975), desde que os valores de salinidade sejam nulos $(S=0)$

\section{Os efeitos tóxicos dos compostos de amônia}

Os primeiros trabalhos que avaliaram a variação da toxicidade dos compostos de amônia limitaram-se a indicar a evolução dos efeitos tóxicos da amônia total com o crescimento dos valores do $\mathrm{pH}$ ou da temperatura da água (POWERS, 1920; MCCAY; VARS, 1931; MERKENS, 1955; CHIPMAN, 1934; WUHRMAN; WOKER, 1948 apud ERICKSON, 1985). Como ponto de convergência, todos esses trabalhos indicaram que aumentos nos valores do $\mathrm{pH}$ ou na temperatura da água tornavam a amônia total mais tóxica. No entanto, não foram estabelecidas quaisquer considerações acerca dos efeitos tóxicos das diferentes espécies de amônia.

Os trabalhos de Fromm e Gillette (1968) permitiram observar que a espécie $\mathrm{NH}_{3}$ suprime a excreção de amônia endógena através das guelras dos peixes. Dessa forma, a mortalidade poderia ser atribuída às falhas neurológicas e citológicas causadas pelos altos níveis de amônia endógena.

Smart (1976), por sua vez, identificou que os prejuízos causados nas guelras e brânquias comprometiam o sistema respiratório dos peixes e que as mortes eram consequência de eventuais asfixias.

Os trabalhos desenvolvidos por Hazel, Thomsen e Meith (1971), Colt e Tchobanoglous (1976), Roseboom e Richey (1977), Rienbold e Pescitelli (1982), Thurston e Russo (1983), e Thurston, Russo e Phillips (1983) demostraram que a toxicidade da parcela de amônia não-ionizada diminui com o aumento da temperatura.

Tabela 2 - Valores percentuais de amônia não-ionizada para águas com salinidade de $10 \mathrm{~g} / \mathrm{kg}$

doces

\begin{tabular}{|llllllll}
\hline Temperatura $\left({ }^{\circ} \mathrm{C}\right)$ & \multicolumn{7}{c}{$\mathrm{pH}$} \\
\cline { 2 - 8 } & 6,00 & 6,50 & 7,00 & 7,50 & 8,00 & 8,50 & 9,00 \\
\hline 0 & 0,01 & 0,03 & 0,08 & 0,26 & 0,82 & 2,55 & 7,64 \\
\hline 10 & 0,02 & 0,06 & 0,19 & 0,59 & 1,83 & 5,56 & 15,71 \\
\hline 20 & 0,04 & 0,13 & 0,40 & 1,24 & 3,82 & 11,16 & 28,43 \\
\hline 30 & 0,08 & 0,25 & 0,80 & 2,48 & 7,46 & 20,30 & 44,62 \\
\hline 40 & 0,16 & 0,49 & 1,54 & 4,71 & 13,51 & 33,06 & 60,96 \\
\hline
\end{tabular}

Tabela 3 - Valores percentuais de amônia não-ionizada para águas com salinidade de $20 \mathrm{~g} / \mathrm{kg}$

\begin{tabular}{lccccccc} 
Temperatura $\left({ }^{\circ} \mathrm{C}\right)$ & \multicolumn{7}{c}{$\mathrm{pH}$} \\
\cline { 2 - 8 } & 6 & 6,5 & 7 & 7,5 & 8 & 8,5 & 9 \\
\hline 0 & 0,01 & 0,02 & 0,07 & 0,22 & 0,71 & 2,20 & 6,63 \\
\hline 10 & 0,02 & 0,05 & 0,16 & 0,51 & 1,59 & 4,87 & 13,94 \\
\hline 20 & 0,04 & 0,11 & 0,35 & 1,09 & 3,38 & 9,95 & 25,90 \\
\hline 30 & 0,07 & 0,23 & 0,71 & 2,22 & 6,70 & 18,50 & 41,78 \\
\hline 40 & 0,14 & 0,44 & 1,39 & 4,26 & 12,35 & 30,82 & 58,48 \\
\hline
\end{tabular}

\begin{tabular}{|lccccccc|}
\hline Temperatura $\left({ }^{\circ} \mathrm{C}\right)$ & \multicolumn{8}{c|}{$\mathrm{pH}$} \\
\cline { 2 - 8 } & 6 & 6,5 & 7 & 7,5 & 8 & 8,5 & 9 \\
\hline 0 & 0,01 & 0,02 & 0,08 & 0,24 & 0,76 & 2,36 & 7,10 \\
\hline 10 & 0,02 & 0,06 & 0,17 & 0,55 & 1,70 & 5,20 & 14,77 \\
\hline 20 & 0,04 & 0,12 & 0,37 & 1,16 & 3,59 & 10,53 & 27,11 \\
\hline 30 & 0,08 & 0,24 & 0,75 & 2,35 & 7,06 & 19,37 & 43,17 \\
\hline 40 & 0,15 & 0,47 & 1,46 & 4,48 & 12,92 & 31,93 & 59,73 \\
\hline
\end{tabular}

Tabela 4 - Valores percentuais de amônia não-ionizada para águas com salinidade de $30 \mathrm{~g} / \mathrm{kg}$

\begin{tabular}{|cccccccc} 
Temperatura $\left({ }^{\circ} \mathrm{C}\right)$ & \multicolumn{7}{c}{$\mathrm{pH}$} \\
\cline { 2 - 8 } & 6 & 6,5 & 7 & 7,5 & 8 & 8,5 & 9 \\
\hline 0 & 0,01 & 0,02 & 0,07 & 0,21 & 0,66 & 2,05 & 6,20 \\
\hline 10 & 0,02 & 0,05 & 0,15 & 0,48 & 1,49 & 4,57 & 13,16 \\
\hline 20 & 0,03 & 0,10 & 0,33 & 1,03 & 3,18 & 9,42 & 24,73 \\
\hline 30 & 0,07 & 0,21 & 0,67 & 2,10 & 6,35 & 17,65 & 40,40 \\
\hline 40 & 0,13 & 0,42 & 1,32 & 4,05 & 11,79 & 29,70 & 57,20 \\
\hline
\end{tabular}


As pesquisas de Robinson-Wilson e Seim (1975), Lloyd e Herbert (1960), Armstrong et al. (1978), McCormick, Broderius e Fiandt (1984) e Broderius et al. (1985) permitiram identificar uma redução na toxicidade da parcela não-ionizada com incrementos nos valores de $\mathrm{pH}$.

Mesmo com a diminuição da toxicidade da porção não-ionizada da amônia com aumentos nos valores de temperatura ou pH, essa espécie de amônia é substancialmente ainda mais tóxica que a forma ionizada.

Rubin e Elmaraghy (1977), ao realizarem bioensaios estáticos com salmões, concluíram que para valores de $\mathrm{pH}$ variando entre 7,4 e 7,5 a espécie $\mathrm{NH}_{3}$ é 56 vezes mais tóxica que a $\mathrm{NH}_{4}^{+}$.

Thurston, Russo e Vinogradov (1981) avaliaram os efeitos tóxicos dos compostos de amônia sobre algumas espécies de peixes e concluíram que alguma toxicidade pode ser atribuída à amônia ionizada. No entanto, para altas concentrações de nitrogênio amoniacal total, quando a toxicidade da espécie $\mathrm{NH}_{4}{ }^{+}$pode ser identificada, a espécie $\mathrm{NH}_{3}$ é de 300 a 400 vezes mais tóxica.

\section{Padrões de qualidade ambiental}

\section{A evolução dos padrões brasileiros}

Por quase duas décadas, o principal instrumento legal voltado para a regulação da qualidade das águas no Território Nacional foi a Resolução Conama 20, editada em 16 de junho de 1986 (BRASIL, 1986).

A Resolução Conama 20/1986 dividia as águas no território nacional em doces (salinidade inferior à 0,05\%), salobras (salinidade entre 0,05 e 3\%) e salinas (salinidade superior a $3 \%$ ) e em nove classes, com os respectivos padrões de qualidade a serem mantidos nos corpos d'água em função dos usos preponderantes.

Para os compostos amoniacais, a Resolução Conama 20/1986 estabelecia os padrões de qualidade mostrados na Tabela 5.

Tabela 5 - Teores limites para os compostos amoniacais segundo a Resolução Conama 20

\begin{tabular}{lccc} 
Corpo d'água & Classe & Parâmetro & Limite $\left(\mathrm{mg}^{-\mathrm{L}^{-1}}\right)$ \\
Doce & Especial & $(1)$ & - \\
& 1 & Amônia não-ionizada & 0,02 \\
& 2 & Amônia não-ionizada & 0,02 \\
& 3 & Nitrogênio amoniacal & $1,00^{(3)}$ \\
& 4 & (2) & - \\
Salino & 5 & Amônia não-ionizada & 0,40 \\
& 6 & Amônia não-ionizada & 0,40 \\
Salobro & 7 & Amônia não-ionizada & 0,40 \\
& 8 & Amônia não-ionizada & 0,40 \\
\hline
\end{tabular}

Fonte: Brasil (1986).

(1) Não é permitida a presença de compostos amoniacais; (2) Não são fixados limites para os compostos amoniacais; ${ }^{(3)}$ Nitrogênio amoniacal expresso como nitrogênio.
Adicionalmente, a Resolução Conama 20/1986, estabelecia como padrão de lançamento de efluentes a concentração máxima de amônia total de $5 \mathrm{mg} \mathrm{N} \mathrm{L}^{-1}$.

A Resolução Conama 20/1986 foi revogada em 17 de março de 2005, com a edição da Resolução Conama 357 (BRASIL, 2005). Essa nova Resolução conservou a divisão das águas do Território Nacional em função da salinidade e criou, em função de revisão dos possíveis usos dos diferentes corpos d'água, duas novas classes para as águas salinas e salobras. As águas doces, no entanto, continuaram sendo divididas entre classes Especial, 1, 2, 3 e 4.

Para cada classe de uso foi estabelecido um novo padrão de qualidade a ser mantido no corpo d'água. Os novos limites estabelecidos para os compostos de amônia estão apresentados na Tabela 6.

A Resolução Conama 357/2005 estabelece, em seu Artigo 10, que os valores máximos estabelecidos para cada uma das classes de enquadramento deverão ser obedecidos nas condições de vazão de referência (vazão do corpo hídrico utilizada como base para o processo de gestão). No entanto, admite-se que os valores máximos admissíveis dos compostos de amônia poderão ser alterados em função das condições naturais, ou quando estudos ambientais específicos, que considerarem os efeitos da poluição difusa, comprovarem que os novos limites não acarretarão prejuízos para os usos previstos no enquadramento do corpo de água. Adicionalmente, a Resolução 357/2005 define que para águas doces de classes 1 e 2 que apresentarem o nitrogênio como fator limitante do processo de eutrofização, o valor de nitrogênio total não deverá superar 1,27 mgN. $\mathrm{L}^{-1}$ em ambientes lênticos e 2,18 mg. $L^{-1}$ em ambientes lóticos.

Como padrão de lançamento de efluentes, a Resolução 357/2005 fixou como limite de amônia total a concentração de 20,0 mgN. $\mathrm{L}^{-1}$.

Em 3 de abril de 2008, o Conama editou a Resolução 397, por meio da qual modificou os limites estabelecidos como padrão de lançamento (BRASIL, 2008). Com essa Resolução, o parâmetro nitrogênio amoniacal total deixou de ser aplicável como regulador da qualidade de efluentes finais produzidos por sistemas de tratamento de esgotos sanitários; no entanto, o limite de 20,0 mgN.L-1 continuou válido para efluentes industriais. Adicionalmente, a Resolução 397/2008, em seu Artigo 2, estabelece que o Conama criará grupo de trabalho para, no prazo máximo de 180 dias, apresentar propostas complementares sobre condições e padrões de lançamento de efluentes para o setor de saneamento.

Segundo Costa (2008), considerando-se a concentração média de nitrogênio presente nos esgotos sanitários típicos do Brasil, o padrão proposto pela Resolução 357/2005 não poderia ser atingido com a implementação dos processos convencionais de tratamento mais comumente empregados no país, tornando-se compulsória a adoção de sistemas terciários de tratamento de esgotos, sistemas notadamente 
mais sofisticados e onerosos. Essa imposição seria frontalmente contrária ao conceito de metas progressivas e a necessidade de universalização dos serviços de saneamento, conforme estabelecido pela Política Nacional de Saneamento (BRASIL, 2007).

\section{Padrões ambientais norte-americanos para os compostos de amônia}

Importantes considerações podem ser feitas sobre padrões brasileiros para os compostos de amônia a partir da análise da evolução dos padrões norte-americanos.

Os padrões fixados no Brasil pela Resolução Conama 20/1986 consistiam em valores-limite para a concentração de amônia total ou de amônia não-ionizada nos diferentes tipos de corpos d'água, independentemente das suas características físicas e químicas. Essa mesma lógica orientou, por muito tempo, os padrões norte-americanos para amônia.

Até 1985, a United States Environmental Protection Agency (Usepa) recomendava que os estados norte-americanos respeitassem uma concentração-limite de 0,02 mgN. $\mathrm{L}^{-1}$ de amônia nãoionizada nos corpos d'água doce. Tal concentração representa aproximadamente $10 \%$ da concentração reportada como letal para uma espécie de truta (Rainbow trout fry) e tinha por objetivo a proteção dos organismos aquáticos considerados mais sensíveis (REIS, 1997).

A adoção da amônia não-ionizada como parâmetro regulador da qualidade se sustentava no fato de ser reconhecidamente a espécie mais tóxica de amônia. No entanto, o aprofundamento do entendimento do comportamento da toxicidade dessa espécie de amônia, no entanto, lançou nova perspectiva para a construção dos parâmetros reguladores de qualidade como diferentes estudos evidenciaram o decréscimo dos efeitos tóxicos da fração não-ionizada de amônia com aumentos dos valores de $\mathrm{pH}$ e temperatura (aspecto sumariamente discutido na seção seguinte deste trabalho), passou a ser aceito que corpos d'água mais quentes e com valores mais elevados de temperatura e $\mathrm{pH}$ fossem regulados por padrões de qualidade menos rigorosos.

Dessa forma, a partir de 1985, as concentrações de amônia nãoionizada passaram a variar em função dos valores de $\mathrm{pH}$ e temperatura dos corpos d'água. Tal abordagem tem norteado a definição dos padrões de qualidade no Canadá e em diferentes países da Europa (REIS, 1997).

Para os corpos de água salina, a Usepa estabelece limites para as concentrações de amônia total em função dos valores de $\mathrm{pH}$, temperatura e salinidade dos corpos d'água. Diferentemente da influência do $\mathrm{pH}$ e da temperatura do corpo d'água, aumentos na salinidade diminuem as concentrações da fração não-ionizada de amônia. Dessa forma, em águas salinas são permitidas maiores concentrações de amônia total para uma mesma concentração de amônia não-ionizada. Também para as águas salinas, o padrão de qualidade estabelecido no
Canadá reproduz a abordagem adotada no padrão norte-americano (REIS, 1997).

As Tabelas 7 a 9 apresentam a versão mais recente dos padrões norte-americanos para os compostos de amônia em águas doces (UNITED STATES ENVIRONMENTAL PROTECTION AGENCY,

Tabela 6 - Teores limites para os compostos amoniacais segundo a Resolução Conama 357

\begin{tabular}{|c|c|c|c|}
\hline $\begin{array}{l}\text { Corpo } \\
\text { d'água }\end{array}$ & Classe & Parâmetro & Limite $\left(m g \cdot L^{-1}\right)$ \\
\hline \multirow[t]{5}{*}{ Doce } & Especial & (1) & - \\
\hline & 1 & $\begin{array}{l}\text { Nitrogênio } \\
\text { amoniacal } \\
\text { total }\end{array}$ & $\begin{array}{c}3,7 \mathrm{mgN} . \mathrm{L}^{-1}, \text { para } \mathrm{pH} \leq 7,5 \\
2,0 \mathrm{mgN} \cdot \mathrm{L}^{-1} \text {, para } 7,5<\mathrm{pH} \leq 8,0 \\
1,0 \mathrm{mgN} \cdot \mathrm{L}^{-1}, \text { para } 8,0<\mathrm{pH} \leq 8,5 \\
0,5 \mathrm{mgN} . \mathrm{L}^{-1}, \text { para } \mathrm{pH}>8,5\end{array}$ \\
\hline & 2 & $\begin{array}{l}\text { Nitrogênio } \\
\text { amoniacal } \\
\text { total }\end{array}$ & $\begin{array}{c}3,7 \mathrm{mgN} . \mathrm{L}^{-1}, \text { para } \mathrm{pH} \leq 7,5 \\
2,0 \mathrm{mgN} \cdot \mathrm{L}^{-1} \text {, para } 7,5<\mathrm{pH} \leq 8,0 \\
1,0 \mathrm{mgN} \cdot \mathrm{L}^{-1} \text {, para } 8,0<\mathrm{pH} \leq 8,5 \\
0,5 \mathrm{mgN} . \mathrm{L}^{-1}, \text { para } \mathrm{pH}>8,5\end{array}$ \\
\hline & 3 & $\begin{array}{l}\text { Nitrogênio } \\
\text { amoniacal } \\
\text { total }\end{array}$ & $\begin{array}{c}13,3 \mathrm{mgN} \cdot \mathrm{L}^{-1}, \text { para } \mathrm{pH} \leq 7,5 \\
5,6 \mathrm{mgN} \cdot \mathrm{L}^{-1} \text {, para } 7,5<\mathrm{pH} \leq 8,0 \\
2,2 \mathrm{mgN} \cdot \mathrm{L}^{-1} \text {, para } 8,0<\mathrm{pH} \leq 8,5 \\
1,0 \mathrm{mgN} \cdot \mathrm{L}^{-1}, \text { para } \mathrm{pH}>8,5\end{array}$ \\
\hline & 4 & (2) & - \\
\hline \multirow[t]{4}{*}{ Salino } & Especial & (1) & - \\
\hline & 1 & $\begin{array}{l}\text { Nitrogênio } \\
\text { amoniacal } \\
\text { total }\end{array}$ & $0,40 \mathrm{mgN} \cdot \mathrm{L}^{-1}$ \\
\hline & 2 & $\begin{array}{l}\text { Nitrogênio } \\
\text { amoniacal } \\
\text { total }\end{array}$ & $0,70 \mathrm{mgN} \cdot \mathrm{L}^{-1}$ \\
\hline & 3 & (2) & - \\
\hline \multirow[t]{4}{*}{ Salobro } & Especial & (1) & - \\
\hline & 1 & $\begin{array}{l}\text { Nitrogênio } \\
\text { amoniacal } \\
\text { total }\end{array}$ & $0,40 \mathrm{mgN} \cdot \mathrm{L}^{-1}$ \\
\hline & 2 & $\begin{array}{l}\text { Nitrogênio } \\
\text { amoniacal } \\
\text { total }\end{array}$ & $0,70 \mathrm{mgN} \cdot \mathrm{L}^{-1}$ \\
\hline & 3 & (2) & - \\
\hline
\end{tabular}

Fonte: Brasil (2005)

(1) Nas águas de classe especial deverão ser mantidas as condições naturais do corpo de água; (2) não são fixados limites para os compostos amoniacais.

Tabela 7 - Critério Agudo para as concentrações de amônia proposto pela Usepa para águas doces

\begin{tabular}{|ccc|}
\multicolumn{3}{c}{ Concentrações de amônia total $\left(\mathrm{mg} \cdot \mathrm{L}^{-1}\right)$} \\
$\mathrm{pH}$ & Salmões presentes & Salmões ausentes \\
\hline 6,5 & 32,60 & 48,80 \\
\hline 7,0 & 24,10 & 36,10 \\
\hline 7,5 & 13,30 & 19,90 \\
\hline 8,0 & 5,62 & 8,40 \\
\hline 8,5 & 2,14 & 3,20 \\
9,0 & 0,885 & 1,32 \\
\hline
\end{tabular}

Fonte: United States Environmental Protection Agency (1999). 
Tabela 8 - Critério Crônico para as concentrações de amônia proposto pela Usepa para águas doces, considerando-se a presença de peixes nos estágios preliminares de vida

\begin{tabular}{|c|c|c|c|c|c|c|c|c|c|c|}
\hline \multicolumn{11}{|c|}{ Concentrações de amônia total $\left(\mathrm{mg} \cdot \mathrm{L}^{-1}\right)$} \\
\hline \multirow{2}{*}{$\mathrm{pH}$} & \multicolumn{10}{|c|}{ Temperatura $\left({ }^{\circ} \mathrm{C}\right)$} \\
\hline & 0 & 14 & 16 & 18 & 20 & 22 & 24 & 26 & 28 & 30 \\
\hline 6,5 & 6,67 & 6,67 & 6,06 & 5,33 & 4,68 & 4,12 & 3,62 & 3,18 & 2,80 & 2,46 \\
\hline 7,0 & 5,91 & 5,91 & 5,37 & 4,72 & 4,15 & 3,65 & 3,21 & 2,82 & 2,48 & 2,18 \\
\hline 7,5 & 4,36 & 4,36 & 3,97 & 3,49 & 3,06 & 2,69 & 2,37 & 2,08 & 1,83 & 1,61 \\
\hline 8,0 & 2,43 & 2,43 & 2,21 & 1,94 & 1,71 & 1,50 & 1,32 & 1,16 & 1,02 & 0,897 \\
\hline 8,5 & 1,09 & 1,09 & 0,990 & 0,870 & 0,765 & 0,672 & 0,591 & 0,520 & 0,457 & 0,401 \\
\hline 9,0 & 0,486 & 0,486 & 0,442 & 0,389 & 0,342 & 0,300 & 0,264 & 0,232 & 0,204 & 0,179 \\
\hline
\end{tabular}

Fonte: United States Environmental Protection Agency (1999).

Tabela 9 - Critério Crônico para as concentrações de amônia proposto pela Usepa para águas doces, considerando-se a ausência de peixes nos estágios preliminares de vida

\begin{tabular}{|c|c|c|c|c|c|c|c|c|c|c|}
\hline \multicolumn{11}{|c|}{ Concentrações de amônia total $\left(\mathrm{mg} \mathrm{L}^{-1}\right)$} \\
\hline \multirow{2}{*}{$\mathrm{pH}$} & \multicolumn{10}{|c|}{ Temperatura $\left({ }^{\circ} \mathrm{C}\right)$} \\
\hline & $0-7$ & 8 & 9 & 10 & 11 & 12 & 13 & 14 & 15 & 16 \\
\hline 6,5 & 10,8 & 10,1 & 9,51 & 8,92 & 8,36 & 7,84 & 7,35 & 6,89 & 6,46 & 6,06 \\
\hline 7,0 & 9,60 & 9,00 & 8,43 & 7,91 & 7,41 & 6,95 & 6,52 & 6,11 & 5,73 & 5,37 \\
\hline 7,5 & 7,09 & 6,64 & 6,23 & 5,84 & 5,48 & 5,13 & 4,81 & 4,51 & 4,23 & 3,97 \\
\hline 8,0 & 3,95 & 3,70 & 3,47 & 3,26 & 3,05 & 2,86 & 2,68 & 2,52 & 2,36 & 2,21 \\
\hline 8,5 & 1,77 & 1,66 & 1,55 & 1,46 & 1,37 & 1,26 & 1,20 & 1,13 & 1,06 & 0,990 \\
\hline 9,0 & 0,790 & 0,740 & 0,694 & 0,651 & 0,610 & 0,572 & 0,536 & 0,503 & 0,471 & 0,442 \\
\hline
\end{tabular}

Fonte: United States Environmental Protection Agency (1999).

1999). A Tabela 7 apresenta os limites para as concentrações médias horárias de amônia, valores máximos permissíveis para as concentrações de amônia total num curso d'água que não devem ser superados mais de uma vez a cada três anos. Esses padrões, definidos pela Usepa como 'Critério agudo', diferenciam, ainda, as concentrações máximas de amônia para cursos d'água com e sem a presença de salmões, espécie muito sensível aos compostos de amônia.

As Tabelas 8 e 9, por sua vez, apresentam os limites para as concentrações médias de amônia total correspondentes a um período de três dias. Esses limites, definidos pela Usepa como 'Critério crônico', apresentam valores de concentração que não devem ser superados em uma vez a cada três anos, distinguindo ainda valores limites para corpos d'água com e sem a presença de peixes nos estágios preliminares de vida.

Os padrões estabelecidos pela Usepa estabelecem, ainda, que as concentrações médias de amônia total correspondentes a um período de quatro dias não devem exceder 2,5 vezes as concentrações limites estabelecidas pelo 'Critério crônico'.

Os padrões americanos para os compostos de amônia em águas salinas (UNITED STATES ENVIRONMENTAL PROTECTION AGENCY, 1989) estão apresentados nas Tabelas 10 e 11. A Tabela 10 apresenta os limites para as concentrações médias horárias de amônia correspondentes aos valores máximos permissíveis para as concentrações de amônia total num curso d'água; esses valores não devem ser superados mais de uma vez a cada três anos. Esses padrões, dependentes dos valores de $\mathrm{pH}$, temperatura e salinidade do corpo d'água, são denominados pela Usepa como 'Critério das concentrações máximas'.

Já a Tabela 11 apresenta os limites para as concentrações médias de amônia total correspondentes a um período de quatro dias. Esses limites, definidos pela Usepa como "Critério das concentrações contínuas", apresentam valores de concentração que não devem ser superados mais de uma vez a cada três anos.

\section{Discussão}

As limitações dos padrões estabelecidos pela antiga Resolução Conama 20/1986 para os compostos de amônia em efluentes a corpos d'água doce já foram discutidas por Reis (1997) e Reis e Mendonça (1998; 1999A; 1999B). Tais limitações podem ser sumarizadas da seguinte forma:

- diferentes parâmetros eram utilizados para a definição dos padrões de qualidade. Enquanto para corpos d'água classes 1 e 2 o padrão de qualidade era definido em termos de amônia não-ionizável, os corpos d'água classe 3 e os efluentes eram 
Tabela 10 - Critério das concentrações máximas para amônia total proposto pela Usepa para águas salinas

\begin{tabular}{cccccccccc} 
& \multicolumn{7}{c}{ Temperatura $\left({ }^{\circ} \mathrm{C}\right)$} \\
\cline { 2 - 9 } & 0 & 5 & 10 & 15 & 20 & 25 & 30 & 35 \\
\hline 7,0 & 270 & 191 & 131 & 92 & 62 & 44 & 29 & 21 \\
\hline 8,0 & 27 & 19 & 13 & 9,4 & 6,4 & 4,6 & 6,1 & 2,3 \\
\hline 9,0 & 2,9 & 2,1 & 1,5 & 1,1 & 0,85 & 0,67 & 0,52 & 0,44 \\
\hline 7,0 & 291 & 200 & 137 & 96 & 64 & 44 & 31 & 21 \\
\hline 8,0 & 29 & 20 & 14 & 9,8 & 6,7 & 4,8 & 3,3 & 2,3 \\
\hline 9,0 & 3,1 & 2,3 & 1,6 & 1,2 & 0,87 & 0,69 & 0,54 & 0,44 \\
\hline 7,0 & 312 & 208 & 148 & 102 & 71 & 48 & 33 & 23 \\
\hline 8,0 & 31 & 21 & 15 & 10 & 7,3 & 5,0 & 3,5 & 2,5 \\
\hline 9,0 & 3,3 & 2,3 & 1,7 & 1,2 & 0,94 & 0,71 & 0,56 & 0,46 \\
\hline
\end{tabular}

Fonte: United States Environmental Protection Agency (1989).

regulados em função das concentrações de amônia total. A utilização de diferentes parâmetros reguladores de qualidade tornava mais difícil a confrontação dos padrões das diferentes classes ou a avaliação do efeito das concentrações de amônia nos efluentes sobre as concentrações de amônia nos corpos d'água. Em ambos os casos, seria indispensável o entendimento do equilíbrio químico entre as diferentes espécies de amônia. É interessante observar, ainda, que os termos amônia total e nitrogênio amoniacal, ambos indicando a soma das diferentes espécies de amônia, eram indistintamente usados no corpo da Resolução 20/1986;

- a variação da toxicidade dos compostos de amônia com as condições do pH e da temperatura da água era ignorada;

- o teor-limite de $5 \mathrm{mgN} . \mathrm{L}^{-1}$ estabelecido para efluentes revestia-se de rigor elevado. Sob certas condições de pH, temperatura e vazão de efluentes e cursos d'água, o teor-limite estabelecido para o efluente ( $5 \mathrm{mg} / \mathrm{L}-\mathrm{N})$ poderia ser superado em muitas vezes, sem que os limites estabelecidos para os cursos d'água fossem alcançados, independentemente da classe do corpo d'água;

- $\quad$ para determinados valores de $\mathrm{pH}$ e temperatura, os padrões estabelecidos para as classes 1 e 2 eram menos rigorosos do que aquele estabelecido para a classe 3.

Para corpos d'água salinos ou salobros é interessante observar que as concentrações máximas aceitáveis de amônia total eram idênticas, ignorando-se qualquer influência da salinidade sobre a distribuição ou sobre os efeitos tóxicos das diferentes espécies de amônia.

As resoluções Conama 357/2005 e 397/2008 corrigem várias das limitações apresentadas pela Resolução 20/1986. Os avanços
Tabela 11 - Critério das concentrações contínuas para amônia proposto pela Usepa para águas salinas

\begin{tabular}{ccccccccc}
\multicolumn{8}{c}{ pH } & \multicolumn{7}{c}{ Temperatura $\left({ }^{\circ} \mathrm{C}\right)$} \\
\cline { 2 - 9 } & 0 & 5 & 10 & 15 & 20 & 25 & 30 & 35 \\
\hline 7,0 & 41 & 29 & 20 & 14 & 9,4 & 6,6 & 4,4 & 3,1 \\
\hline 8,0 & 4,1 & 2,9 & 2,0 & 1,40 & 0,97 & 0,69 & 0,47 & 0,34 \\
\hline 9,0 & 0,44 & 0,31 & 0,23 & 0,17 & 0,13 & 0,10 & 0,08 & 0,07 \\
\hline 7,0 & 44 & 30 & 21 & 14 & 9,7 & 6,6 & 4,7 & 3,1 \\
\hline 8,0 & 4,4 & 3,0 & 2,1 & 1,5 & 1,0 & 0,72 & 0,50 & 0,34 \\
\hline 9,0 & 0,47 & 0,34 & 0,24 & 0,18 & 0,13 & 0,10 & 0,08 & 0,07 \\
\hline 7,0 & & & Salinidade $=30 \mathrm{~g} / \mathrm{kg}$ & & & \\
\hline 8,0 & 4,7 & 31 & 22 & 15 & 11 & 7,2 & 5,0 & 3,4 \\
\hline 9,0 & 0,50 & 0,34 & 0,26 & 0,19 & 0,14 & 0,11 & 0,08 & 0,07 \\
\hline
\end{tabular}

Fonte: United States Environmental Protection Agency (1989).

conseguidos com as novas resoluções podem ser resumidos da seguinte maneira:

- o nitrogênio amoniacal total (ou amônia total) passou a ser o parâmetro regulador da qualidade dos corpos d'água das diferentes classes e do lançamento de efluentes;

- $\quad$ os teores limites de nitrogênio amoniacal total não são mais independentes das condições de pH dos corpos d'água doce. Para todas as classes de corpos d'água, os teores máximos admissíveis de nitrogênio amoniacal são estabelecidos para as diferentes faixas de $\mathrm{pH}$;

- os limites estabelecidos para os corpos d'água classes 1 e 2 são, invariavelmente, mais rigorosos que os limites estabelecidos para os corpos d'água classes 3;

- $\quad$ as concentrações máximas admissíveis de amônia total nos efluentes industriais foram aumentadas em quatro vezes, passando de 5 $\mathrm{mgN} . \mathrm{L}^{-1}$ para $20 \mathrm{mgN} \cdot \mathrm{L}^{-1}$. Adicionalmente, não são mais fixados limites para a concentração de amônia total nos efluentes produzidos pelos sistemas de tratamento de esgotos sanitários.

A comparação entre os atuais padrões norte-americanos e os valores propostos pela Resolução 357/2005 para águas doces permite o estabelecimento das seguintes observações:

- para os corpos d'água classes 1 e 2, os padrões estabelecidos pela Resolução 357/2005 apresentam valores na mesma ordem de grandeza que aqueles propostos pelo critério crônico adotado pela Usepa, considerando a ausência de peixes nos estágios preliminares de vida;

- $\quad$ para valores de $\mathrm{pH}$ superiores a 7,5, o padrão para os corpos d'água classe 3 está muito próximo do critério agudo proposto pela Usepa para águas que apresentam salmões. No entanto, para valores de pH inferiores a 7,5, o padrão brasileiro é mais restritivo. 
A Resolução 357/2005, no entanto, não incorporou a influência da temperatura sobre a distribuição e sobre a toxicidade dos compostos de amônia em corpos d'água doce. Na Tabela 1 pode-se observar que a distribuição das espécies de amônia é muito mais sensível às variações de $\mathrm{pH}$ do que às variações de temperatura. Conforme salienta Erickson (1985), a mesma lógica se observa sobre o comportamento tóxico da amônia, afetado muito mais severamente pelo $\mathrm{pH}$ do que pela temperatura. Ainda assim, os efeitos das variações de temperatura podem ser consideráveis, principalmente se consideradas as variações sazonais e regionais no Território Nacional. Em corpos d'água com salinidade nula e com pH neutro, uma variação de temperatura entre 20 e $30^{\circ} \mathrm{C}$ dobra a quantidade da fração não-ionizada de amônia, embora a concentração dessa espécie de amônia não represente mais do que $2 \%$ da amônia total; para $\mathrm{pH}=9$, a mesma variação de temperatura eleva o percentual da parcela não-ionizada de 28 para aproximadamente $45 \%$.

Os limites estabelecidos na regulamentação brasileira para águas doces classe 3, nos valores de $\mathrm{pH}$ superiores a 7,5, reproduzem os padrões americanos para as águas que apresentam salmões; para valores de $\mathrm{pH}$ inferiores a 7,5, os padrões brasileiros são ainda mais restritivos do que aqueles definidos pelo critério agudo americano. Adicionalmente, os padrões propostos pela Resolução 357/2005 são muito mais conservadores do que os padrões americanos para águas que não apresentam salmões (ver Tabela 7). Dessa forma, mesmo que as águas classe 3 apresentem a pesca amadora como possível utilidade, a definição de um padrão para todo o Território Nacional a partir dos padrões americanos estabelecidos para águas que apresentem peixes sensíveis à amônia corresponde a uma abordagem extremamente conservadora.

Uma avaliação dos limites propostos para as águas salinas permite observar que as alterações introduzidas pela Resolução 357/2005 foram mais modestas. Além da criação de duas novas classes de corpos d'água, essa Resolução dilata as concentrações máximas aceitáveis para uma delas. Os limites propostos, no entanto, não fazem qualquer associação entre os valores de $\mathrm{pH}$, temperatura ou salinidade dos corpos d'água e a distribuição das espécies de amônia e os seus efeitos tóxicos

Conforme observaram Reis (1997), Reis e Mendonça (1998; 1999A; 1999B), o limite de 5 mgN.L-1 , estabelecido pela Resolução 20/1986, para as concentrações de amônia total nos efluentes apresentava-se extremamente rigoroso. Não existia, aparentemente, qualquer base técnica que sustentasse os padrões indicados pela antiga Resolução 20/1986, como também parece não existir para o novo padrão estabelecido para efluentes industriais pela Resolução 357/2005. A revisão do padrão proposto representa, portanto, um avanço, principalmente quando se considera o fato de que foram estabelecidos novos padrões para os corpos receptores, cujos valores passaram a ser função do $\mathrm{pH}$. O aumento do limite para o padrão de lançamento dos efluentes industriais, a supressão do parâmetro nitrogênio amoniacal total como regulador da qualidade de efluentes de estações de tratamento de efluentes sanitários e o aperfeiçoamento dos limites propostos para os corpos receptores vão ao encontro do princípio do desenvolvimento sustentável, pois admitem que a capacidade de assimilação dos corpos receptores pode ser melhor aproveitada.

Os avanços alcançados com as resoluções 357/2005 e 397/2005 em relação à Resolução 20/1986, facilitam o licenciamento de atividades potencialmente produtivas, sem aumento significativo de impactos ambientais potenciais associados à toxicidade dos compostos de amônia sobre a fauna aquática.

\section{Considerações finais}

Neste trabalho, os novos padrões estabelecidos pelo Conama para os compostos de amônia em efluentes e corpos d'água foram apresentados e discutidos. Das discussões precedentes são relevantes as seguintes conclusões:

- a Resolução 357/2005 uniformizou o parâmetro regulador de qualidade para os compostos de amônia, adotando limites máximos aceitáveis para as concentrações de nitrogênio amoniacal total em efluentes e corpos d'água de diferentes tipos e classes;

- $\quad$ para corpos d'água doce foram adotados padrões dependentes dos valores de $\mathrm{pH}$, característica de qualidade de água que afeta severamente o comportamento dos compostos de amônia. Os novos padrões, no entanto, não incorporaram a influência da temperatura sobre a toxicidade, nem a distribuição dos compostos de amônia;

- os padrões propostos para as águas doces classe 1 e 2 apresentam valores na mesma ordem de grandeza daqueles propostos pelo critério crônico adotado pela Usepa, considerando a ausência de peixes nos estágios preliminares de vida. O padrão proposto para águas classe 3 , considerandose valores de $\mathrm{pH}$ superiores a 7,5, está muito próximo do critério agudo proposto pela Usepa para as águas que apresentam salmões;

- as alterações introduzidas pela Resolução 357/2005 para as águas salinas foram modestas. Embora tenha havido dilatação dos limites propostos para uma das classes de corpos d'água salinos, os novos padrões não consideram a importância do pH, da temperatura ou da salinidade sobre a toxicidade ou distribuição das diferentes espécies de amônia;

- a concentração máxima admissível para o nitrogênio amoniacal em efluentes ( $5 \mathrm{mg} / \mathrm{L}-\mathrm{N})$, que se demonstrou extremamente rigorosa para certas combinações de $\mathrm{pH}$, temperatura e razões de diluição do efluente, foi quadruplicada com a edição da Resolução 
357/2005. Adicionalmente, com a edição da Resolução 397/2008, o nitrogênio amoniacal total deixou de constituir parâmetro regulador da qualidade de efluentes de estações de tratamento de efluentes sanitários. Não existe, aparentemente, qualquer base técnica que sustente os antigos ou os novos padrões de qualidade de efluentes estabelecidos pelo Conama.

\section{Referências}

ARMSTRONG, D.A. et al. Interaction of ionized and un-ionized ammonia on short-term survival and growth of prawn larvae, macrobrachium rosenbergii. Biological Bulletin, n. 154, p. 15-31, 1978.

BRASIL. Resolução CONAMA no 397/2008, de 3 de abril de 2008. Altera o inciso II do parágrafo $4^{\circ}$ e a Tabela $X$ do parágrafo $5^{\circ}$, ambos do art. 34 da Resolução do Conselho Nacional do Meio Ambiente, CONAMA n 357, de 2005, que dispõe sobre a classificação dos corpos de água e diretrizes ambientais para o seu enquadramento, bem como estabelece as condições e padrões de lançamento de efluentes. Diário Oficial da União, 7 de abril de 2008, p. 68-69.

Lei no 11.445, de 5 de janeiro de 2007. Estabelece diretrizes nacionais para o saneamento básico; altera as leis n 6.766, de 19 de dezembro de 1979, no 8.036, de 11 de maio de 1990, nº 8.666, de 21 de junho de 1993, no 8.987, de 13 de fevereiro de 1995; revoga a lei $n^{\circ}$ 6.528 , de 11 de maio de 1978 e dá outras providências. Diário Oficial da União, 8 de janeiro de 2007, p. 3-7.

Resolução CONAMA no 357/2005, de 17 de março de 2005. Dispõe sobre a classificação dos corpos de água e diretrizes ambientais para o seu enquadramento, bem como estabelece as condições e padrões de lançamento de efluentes, e dá outras providências. Oficial da União, 18 de março de 2005, p. 58-63.

Resolução CONAMA no 20/1986, de 18 de junho de 1986. Dispõe sobre a classificação das águas doces, salobras e salinas do Território Nacional. Diário Oficial da União, 30 de julho de 1986, p. 11356-11361.

BRODERIUS, S. et al. Toxicity of ammonia to early life stages of the smallmouth bass at four $\mathrm{pH}$ values. Environmental Toxicology and Chemistry, n. 4, p. 87-96, 1985.

CLEGG, S.; WHITFIELD, M. A chemical model of seawater including dissolved ammonia and the stoichiometric dissociation constant of ammonia in estuarine water and seawater from -2 to $40{ }^{\circ} \mathrm{C}$. Geochim. Cosmochim. Acta, v. 59, n. 12, p. 2403-2421, 1995.

COLT, J.; TCHOBANOGLOUS, G. Evaluation of the short-term toxicity of nitrogenous compounds to channel catfish, ictalurus punctatus. Aquaculture, n. 8, p. 209-224, 1976.

COSTA, B.S. Decisão do CONAMA foi pelo bom senso. Abes Informa, n. 67, p. 4,2008

EMERSON, K. et al. Aqueous ammonia equilibrium calculations: effect of $\mathrm{pH}$ and temperature. Journal of the Fisheries Research Board of Canada, n. 12 , p. $2379-2383,1975$
ERICKSON, R.J. An evaluation of mathematical models for the effects of ph and temperature on ammonia toxicity to aquatic organisms. Water Research, n. 19, p. 1047-1058, 1985.

FROMM, P.; GILLETTE, J. Effect of ambient ammonia on blood and nitrogen excretion of Rainbow Trout. Comparative Biochemistry and Physiology, n. 26, p. 887-896, 1968.

HAZEL, C.R.; THOMSEN, W.; MEITH, S.J. Sensitivity of striped bass and stickleback to ammonia in relation to temperature and salinity. California Fish and Game, n. 57, p. 138-153, 1971.

LLOYD, R.; HERBERT, D.W.M. The influence of carbon dioxide on the toxicity of un-ionized ammonia to rainbow trout (salmo gairdnerii richardson). Annals of Applied Biology, n. 48, p. 399-404, 1960.

MCCORMICK, J.H.; BRODERIUS, S.J.; FIANDT, J.T. Toxicity of ammonia to early life stages of the green sunfish lepomis cyanellus. Environmental Pollution, series A, n. 36, p. 147-163, 1984.

REINBOLD, K.A.; PESCITELLI, S.M. Effects of exposure to ammonia on sensitive life stages of aquatic organisms. Champaign, Illinois: Illinois Natural History Survey, 1982.

REIS, J.A.T. Estudo dos padrões para compostos amoniacais em efluentes e cursos d'água interiores. Dissertação (Mestrado em Engenharia Ambiental) - Ufes, 1997.

REIS, J.A.T.; MENDONÇA, A.S.F. Amônia em efluentes e mananciais de água doce - Uma avaliação dos limites impostos pelo CONAMA. In: CONGRESSO BRASILEIRO DE ENGENHARIA SANITÁRIA AMBIENTAL, 20, 1997, Anais..., Rio de Janeiro: ABES, 1999A.

A influência dos valores de $\mathrm{pH}$ e temperatura sobre a toxicidade da amônia e sua importância na definição de padrões ambientais para corpos d'água. In: CONGRESSO BRASILEIRO DE ENGENHARIA SANITÁRIA AMBIENTAL, 20, 1997, Anais..., Rio de Janeiro: Associação Brasileira de Engenharia Sanitária e Ambiental - Abes, 1999B.

Análise dos padrões para os compostos amoniacais segundo a Resolução CONAMA 20/86. Revista de Engenharia Sanitária e Ambiental, v. 3, n. 4, p. $146-154,1998$

ROBINSON-WILSON, E.F.; SEIM, W.K. The lethal and sublethal effects of a zirconium process effluent on juvenile salmonids. Water Resources Bulletin, n. 11, p. 975-986, 1975

ROSEBOOM, D.P.; RICHEY, D.L. Acute toxicity of residual chlorine and ammonia to some native Illinois fishes. Urbana, Illinois: Illinois State Water Survey, 1977 
RUBIN, A.J.; ELMARAGHY, G.A. Studies on the toxicity of ammonia, nitrate and their mixtures to guppy fry. Water Research, n. 11, p. 927935, 1977.

SMART, G. The effect of ammonia exposure on gill structure of the rainbow trout (salmo gairdneri). Journal of Fish Biology, n. 8, p. 471-475, 1976.

THURSTON, R.V.; RUSSO, R.C. Acute toxicity of ammonia to rainbow trout. Transactions of the American Fisheries Society, n. 112, p. 696-704, 1983.

THURSTON, R.V.; RUSSO, R.C.; PHILLIPS, G.R. Acute toxicity of ammonia to fathead minnows. Transactions of the American Fisheries Society, n. 112, p. 705-711, 1983.
THURSTON, R.V.; RUSSO, R.C.; VINOGRADOV, G.A. Ammonia toxicity to fishes. effect of ph on the toxicity of the un-ionized ammonia species. Environmental Science and Technology, n. 15, p. 837-840, 1981.

UNITED STATES ENVIRONMENTAL PROTECTION AGENCY. 1999 Update of ambient water quality criteria for ammonia. Washington, DC: Office of Water/Office of Science and Technology, 1999.

UNITED STATES ENVIRONMENTAL PROTECTION AGENCY. Ambient aquatic life water quality criteria for ammonia (salt water) 1989. Rhode Island: Office of Research and Development/Environmental Research Laboratory, 1989. 